\title{
Fenologia do florescimento e características do perfume das flores de Passiflora quadrangularis 1. (maracujá-melão) ${ }^{(1)}$
}

\author{
DANIEL ANTONIO VILLAMIL MONTERO(2), LAURA MARIA MOLINA MELETTI(3), \\ MARCIA ORTIZ MAYO MARQUES(3)
}

\begin{abstract}
RESUMO
Passiflora quadrangularis L. é uma espécie originária do neotrópico, conhecida no Brasil como maracujá-melão devido ao tamanho e formato dos seus frutos. Tem sido amplamente disseminada nas regiões tropicais do mundo onde é produzida em pequena escala para comercialização dos frutos, o que ocorre bem próximo às regiões de cultivo, em função da dificuldade de conservação pós-colheita. As plantas são trepadeiras bastante vigorosas, com flores abundantes, grandes e perfumadas, o que amplia o seu valor e a torna particularmente interessante para caramanchões e cercas-vivas. O uso efetivo de passifloras no mercado de plantas ornamentais depende de estudos da fenologia floral. Neste trabalho foram estudadas algumas características da fenologia floral e o perfume das flores de P. quadrangularis, sob cultivo protegido. São apresentados os dados relativos ao período de floração, picos de florescimento e intensidade relativa das flores, bem como algumas características do perfume floral. Conclui-se que a espécie representa uma nova alternativa de cultivo para fins ornamentais, por apresentar múltiplas flores em antese simultânea, abundantes, grandes, fragrantes e coloridas, com longo período de floração no ano, além de frutos comestíveis, folhas exuberantes e medicinais que oferecem amplo sombreamento para áreas externas de lazer e/ou outras plantas cultivadas.
\end{abstract}

Palavras-chave: Passifloraceae, Badea, ornamental, fragrância floral.

\begin{abstract}
Passiflora quadrangularis L. it's a neotropical species, commonly known in Brazil as the melon passion fruit due to the size and format of its fruits. Currently, it has been widely disseminated throughout the tropics and it is commercially produced on a small scale, but mostly locally consumed because the fruits bruise easily when shipped. The plants of $P$. quadrangularis are vigorous climbers with abundant foliage and big beautiful scented flowers for which its use as ornamental plant seems particularly interesting. It has been stipulated that for the effective use of passion flowers in the ornamental plant market, studies need to be done on the flowering phenology. For this reason, we investigated some features regarding the flowering phenology and the composition of the scent produced by the flowers of $P$. quadrangularis cultivated at greenhouse. We present data concerning to the flowering period, blossom pick, relative blossom intensity and some characteristics of the flower scent. We conclude that $P$. quadrangularis represents a novel alternative as an ornamental plant in Brazil, because it's abundant, big, scented, colorful, anthesis-simultaneous and flowers with long period of blossom. Also because it's edible fruit and the medicinal properties of the exuberant foliage that could offer a nice shading for outdoor leisure areas and/or shade plants.
\end{abstract}

Keywords: Passifloraceae, floral phenology, ornamental, floral scent.

\section{INTRODUÇÃO}

A família Passifloraceae compreende cerca 650 espécies, divididas entre 18 gêneros, segundo a classificação mais recente proposta por FEUILLET e MACDOUGAL (2003). O gênero Passiflora (L), com aproximadamente 575 espécies, é numérica e economicamente o mais importante. A maioria delas é nativa da América tropical, e só aproximadamente 30 espécies são originarias do velho mundo (ULMER e MACDOUGAL 2004, OCAMPO et al. 2007). O Brasil é centro de diversidade genética do gênero e o segundo país (superado apenas pela Colômbia) com maior número de espécies de Passiflora, sendo conhecidas aproximadamente 120 espécies (BERNACCI 2003, ULMER e MACDOUGAL 2004, VANDERPLNAK 2007, ABREU et al. 2009). Dezenas de passifloras produzem frutos comestíveis (MARTIN e NAKASONE, 1970), alguns largamente apreciados pelos povos americanos, como Passiflora edulis Sims, P. ligularis Juss. e $P$. quadrangularis $\mathrm{L}$.

Como plantas ornamentais, as passifloras produzem grande fascinação pela beleza das flores, que são extremamente variáveis em cor e em tamanho, além de muitas vezes apresentarem perfumes diferenciados. As flores das passifloras são consideradas exóticas e complexas, algumas de coloração forte e brilhante, outras de coloração tênue e suave devido, principalmente, à presença da corona, que caracteriza a família Passifloraceae (ABREU et al. 2009). Igualmente fascinante é a ampla variedade de formatos de folhas dentro do gênero, tendo muitas espécies valor ornamental somente em função da folhagem. Outras características que inserem as passifloras na lista de

\footnotetext{
(1) Recebido em

(2) Universidade Estadual Paulista “Júlio Mesquita Filho" (UNESP), Campus de Botucatu. Faculdade de Ciências Agrárias, Departamento de Horticultura.

(3) Dra.., Pesquisador Científica, Instituto Agronômico de Campinas (IAC)
} 
plantas ornamentais são o número abundante de flores e o florescimento mais de uma vez ao ano (VANDERPLANK 2000, PEIXOTO 2005, JUNQUEIRA e JUNQUEIRA 2006, ROZA et al. 2006, ABREU et al. 2009). Desta forma, o uso das passifloras como plantas ornamentais tem se destacado em vários países e já, desde o século XVII, as passifloras têm sido utilizadas para decorar jardins e estufas, principalmente na Europa e América do Norte.

No Brasil, o mercado das passifloras como plantas ornamentais é praticamente inexplorado, apesar do enorme potencial que existe como centro de origem de muitas das mais belas espécies (PEIXOTO 2005, ABREU et al., 2009, PIRES et al., 2012). Segundo ABREU et al., (2009), para o uso efetivo de passifloras no mercado das plantas ornamentais ainda são necessários estudos da fenologia floral relacionados com período, taxa, pico, intensidade relativa e duração média do florescimento, entre outros. No Brasil, P. quadrangularis é comumente conhecida como maracujá-melão, em função do tamanho e formato do fruto, ou como maracujá-açu, nome de origem tupi-guarani, o que indica que a planta e a fruta eram conhecidas e apreciadas desde os tempos pré-colombianos. Trata-se de uma trepadeira alta, inteiramente glabra, propiciando a formação de caramanchões singularmente umbrosos. Suas folhas são inteiras, largamente ovadas, grandes, com pecíolos glandulares e mais de dez nervuras equidistantes, medindo $10-20 \mathrm{~cm}$ de comprimento por 8-10 cm de largura, abruptamente acuminadas. As flores são solitárias, alvas e purpúreas (KILLIP, 1938; SOUZA e MELETTI, 1997). Alguns autores consideram a espécie nativa da Amazônia e do norte da América do Sul, cultivada em toda a América tropical. MARTIN E NAKASONE (1970) consideram este maracujá um dos mais distribuído por todos os trópicos. Nas Américas, o plantio alastra-se desde o México até Pelotas, no Rio Grande do Sul. No entanto, a espécie prefere clima quente.

Os frutos são de cor amarela quando maduros, oblongo-ovoides, grandes, de $10-30 \mathrm{~cm}$ de comprimento e $10-18 \mathrm{~cm}$ de largura. O mesocarpo do fruto tem gosto de melão e pode ser consumido; segundo MARTINS e NAKASONE (1970), é a única espécie de Passiflora que apresenta esta característica. A polpa em torno das sementes é aromática, pouco ácida e de paladar agradável. A produtividade desta espécie é excelente quando as flores são polinizadas manualmente (MARTIN e NAKASONE 1970). O uso como planta ornamental, ainda não explorado no Brasil, é bastante interessante na formação de caramanchões e cercas-vivas, em chácaras, quintais e locais próprios para eventos, onde o perfume das flores é um adicional qualitativo.

No presente trabalho, objetivou-se estudar algumas das características relacionadas com a fenologia floral e o perfume das flores de $P$. quadrangularis, em condições de cultivo protegido.

\section{MATERIAIS E MÉTODOS}

O estudo foi desenvolvido no Centro Experimental do Instituto Agronômico de Campinas (IAC), durante 2011 e 2012. A manutenção das plantas e a amostragem dos materiais vegetais analisados foram feitas no Núcleo do Jar- dim Botânico do Centro de Recursos Genéticos Vegetais/ IAC, enquanto as análises químicas foram conduzidas no Laboratório de Óleos Essenciais do Centro de Recursos Genéticos Vegetais deste mesmo Instituto.

Para obtenção do material vegetal a ser analisado, mudas de Passiflora quadrangularis pertencentes ao Banco de Germoplasma do IAC, com cerca de $60 \mathrm{~cm}$ de altura, foram plantadas em vasos plásticos pretos de $30 \mathrm{~L}$ de capacidade, no mês de novembro. O substrato utilizado resultou de uma mistura homogeneizada de $100 \mathrm{~kg}$ de substrato orgânico comercial, $75 \mathrm{~kg}$ de fibra de coco, 1 $\mathrm{kg}$ de calcário dolomítico, $1 \mathrm{~kg}$ de superfosfato simples e $0,5 \mathrm{~kg}$ de torta de mamona. As plantas foram mantidas em estufa construída com telado antiafídeo nas laterais e plástico denso transparente na cobertura, irrigadas manualmente três vezes por semana, e conduzidas em sistema de espadeira com um único fio de arame liso a altura de $1,70 \mathrm{~m}$. Quando as plantas atingiram a altura do arame, foram despontadas para induzir a brotação secundária, sendo desbrotadas em seguida, a fim de deixar apenas os dois brotos superiores para formar duas hastes laterais, uma para cada lado do fio, visando à formação de cortinas produtivas com os ramos terciários, segundo o sistema tradicional brasileiro para produção comercial de maracujá (MELETTI et al., 2010). Todos os brotos da haste principal abaixo do arame de sustentação foram retirados manual e periodicamente, para favorecer os ramos produtivos subsequentes. Durante os três primeiros meses de idade, as plantas foram conduzidas com adubo foliar NPK 28-14-14 + micro nutrientes $(0,1 \mathrm{~g} \mathrm{Fe}, 0,05 \mathrm{~g} \mathrm{Mn}, 0,05 \mathrm{~g}$ $\mathrm{Zn}, 0,05 \mathrm{~g} \mathrm{Cu}, 0,02 \mathrm{~g} \mathrm{~B}$ e $0,0005 \mathrm{Mo}$ ), aplicados a cada 15 dias. Seguiu-se a adubação de cobertura com a formulação NPK 20-5-20 à base de 100 g/planta, mensalmente. Durante a floração, foi aplicado adicionalmente $1 \mathrm{~kg}$ de $\mathrm{KCl}$ misturado ao mesmo substrato, completando-se o volume dos vasos até a borda superior e adicionando-se NKP 8-8-8 (liquido), diluído a 7,5ml/ L de água, mais $0,025 \mathrm{~L}$ de $\mathrm{Ca}-\mathrm{Mg}-\mathrm{B}$ por planta, a cada 25 dias.

Foram anotados o número de semanas necessários até o surgimento dos botões florais, o período de floração no ano e o horário de antese no dia. Semanalmente, contabilizou-se o número de dias necessários ao desenvolvimento completo do botão floral, avaliando-se, também, o tamanho máximo do botão floral $(\mathrm{cm})$, o diâmetro máximo da flor $(\mathrm{cm})$ e número total de flores por planta.

Para a caracterização do perfume das flores, a fragrância foi coletada com a técnica de Headspace dinâmico (DHS), adaptado do método descrito por SCHILLING et al. (2004). Para cada amostra, uma flor foi inserida num funil de cristal coberto com uma sacola de poliacetato. Durante uma hora, o ar no interior do sistema foi puxado através de uma armadilha absorvente (Poropak super Q), usando uma bomba de vácuo portátil com fluxo de 100ml/ min. Foram feitas cinco repetições, sempre no mesmo horário. As amostras foram analisadas por cromatografia gasosa acoplada a espectrometria de mesas (CG/EM) e a identificação dos constituintes químicos foi efetuada através da análise comparativa dos espectros de massas das substâncias com o banco de dados do sistema CG-EM (Nist 62.lib) e o índice de retenção de Kovats (ADAMS 1995)- 


\section{RESULTADOS E DISCUSSÃO}

Os primeiros botões florais de P.quadrangularis foram observados após 19 semanas do transplante das mudas, surgindo a partir do mês de abril (Figura 1A). O período de floração estendeu-se de abril até julho do mesmo ano (Figura 1C), quando então os dias curtos de inverno e a temperatura em declínio interromperam a fase reprodutiva das plantas. Neste período de floração, foram observados vários picos de concentração de flores, com intervalos de 30 a 40 dias.

O comportamento reprodutivo da espécie seguiu o padrão das Passifloras tropicais. O florescimento mostrou-se dependente de uma combinação de temperaturas superiores a $18^{\circ} \mathrm{C}$, concordando com SÃO JOSÉ (1994) e confirmando observações de SOUZA e MELETTI (1997), que indicaram a dificuldade para o florescimento da espécie sem um mínimo de 12 horas de luz por dia.

Mas, os resultados obtidos diferiram dos citados por ULMER e MACDOUGAL (2004), que relatam floração de maio até outubro na Venezuela. Muito provavelmente, esta diferença no comportamento seja um dos efeitos da redução do fotoperíodo nos dias de inverno, na região de Campinas (SP).

As condições climáticas do verão paulista permitem que esta combinação de temperatura e luz ocorra antes de abril, sendo comum observá-la já a partir de novembro. Por isso, é bastante provável que o período de florescimento de Passiflora quadrangularis seja bem mais amplo que o observado neste experimento, conforme já indicado por MELETTI et al. (1994). Caso as mudas de maracujá-melão tivessem sido plantadas em setembro, por exemplo, provavelmente o período de florescimento mostrar-se-ia ampliado, iniciando-se em fevereiro ou março. Só que o plantio das mudas deste experimento foi propositalmente tardio (novembro), a fim de evitar possíveis danos aos poucos exemplares da espécie disponíveis no BAG.

De acordo com ULMER e MACDOUGAL (2004), quando $P$. quadrangularis é cultivada em vasos grandes, ela se desenvolve rapidamente, até formar uma planta grande e vigorosa, com ramos de vários metros de comprimento. Nos primeiros meses, a planta permanece na fase juvenil e utiliza toda sua energia para o crescimento vegetativo. Depois disso, numerosas flores desenvolvem-se quando a temperatura noturna varia pouco, com média de $30^{\circ} \mathrm{C}$, sem baixar dos $12^{\circ} \mathrm{C}$ por períodos prolongados. No presente experimento, foram necessários cerca de cinco meses de fase juvenil para a espécie alcançar a maturidade fisiológica para então receber o estímulo fotoperiódico para florescimento.

Diferentemente de outras Passifloras, conforme relatos anteriores publicados por HADDAD e FIGUEROA (1972) e AVILÁN et al. (1989), em P. quadrangularis observa-se que apenas alguns pontos de crescimento são induzidos a formar botões florais. A maioria dos ramos permanece em crescimento vegetativo, mas os ponteiros que entram na fase reprodutiva desenvolvem bem rapidamente seus botões florais, de forma bastante homogênea, chegando inclusive a abrir todos os botões do ramo no mesmo dia (Figura 1B e Figura 2). A antese começou nas primeiras horas da manhã e as flores ficaram abertas até o cair da noite, por um único dia, fechando-se em seguida. As flores que não foram polinizadas degeneraram, seguindo o padrão comum das Passifloras.

O tempo necessário para o desenvolvimento dos botões florais foi 13,4 $\pm 0,9$ dias e a taxa média de desenvolvimento foi de 4,9 $\mathrm{mm}$ por dia (Figura 1D). Isto representa uma espécie vigorosa, possivelmente com acessos tetraploides, isto já seria um comportamento previsto. Estudos de caracterização cromossômica poderiam explicar se este crescimento diferenciado seria efeito da polissomia ou simplesmente por ser uma planta robusta, uma diferenciação observada já no tamanho avantajado de suas sementes e das plântulas resultantes da germinação.

O tempo de desenvolvimento dos botões florais (13 dias no presente trabalho) diferiu dos 21 dias relatados por HADDAD e FIGUEROA (1972), provavelmente devido as diferencias ambientais entre as localidades de experimentação. O tamanho máximo do botão floral observado foi $6,4 \pm 0,27 \mathrm{~cm}$. O diâmetro máximo da flor foi $11,8 \pm 0,16 \mathrm{~cm}$ (Figura 1D). O primeiro pico da florada foi registrado após 28 semanas do início do florescimento, seguido por outros dois (Figura 1C), bem próximos, indicando que se trata de uma espécie com comportamento florístico muito interessante para fins paisagísticos.

O total de flores produzidas numa planta até o final do experimento foi de 58 flores (Figura 1D), o que também pode ser considerado elevado, especialmente se tratando de uma planta cultivada em vaso. Este número de flores por planta, assim como a distribuição do período de floração no ano foram semelhantes aos resultados de KISHORE et al. (2010).

\section{Perfume das flores de $\boldsymbol{P}$. quadrangularis}

O perfume das flores de $P$. quadrangularis é bastante intenso e agradável, devido ao fato de apresentar uma combinação de notas cítricas, doces, frutais e florais que nos brindam uma sensação de bem-estar e harmonia com a natureza. Observou-se que as flores emitem o perfume continuamente desde as primeiras horas da manhã até o final da tarde, com pico de intensidade nas horas mais quentes do dia. Neste sentido, figura especialmente conveniente o uso desta espécie para sombrear e aromatizar áreas externas de lazer, como varandas, quintais e jardins. Nas amostras do perfume, identificaram-se 22 compostos voláteis diferentes (Figura 3) com maior proporção relativa $(\% \mathrm{R})$ de Terpenos $(56,31 \% \mathrm{R})$, Benzenoides e Fenil-propanoides $(22,48 \% \mathrm{R})$. Também, foram identificados em menor proporção compostos de tipo alifático $(8,82 \% \mathrm{R})$ e um composto nitrogenado $(2,5 \% \mathrm{R})$. O composto majoritário no perfume das flores de $P$. quadrangularis foi o Gerâniol, com 43,6\%R. compostos voláteis

\section{Vantagens de $\boldsymbol{P}$. quadrangularis como planta ornamental}

Com base nos resultados, considerou-se que $P$. quadrangularis apresenta várias vantagens do ponto de vista ornamental. As plantas vigorosas, adaptadas às condições de insolação, com flores grandes e vistosas, perfumadas e ainda com frutos comestíveis são bastante interessantes para caramanchões, revestimento de telhados, cercas-vivas, paredes e para proporcionar sombra, quando devidamente conduzidas sobre estruturas adequadas para este 
fim. Suas flores grandes e abundantes, de sépalas e pétalas cor rosa e branca, com coronas compridas, pendentes e de cor violeta-intensa, são indiscutivelmente vistosas e muito atrativas (Figura 2). Somado a isto, o perfume que emana de suas flores, desde os primeiros momentos da manhã até o final da tarde traduz-se numa experiência intensa e agradável, acompanhada de uma sensação de bem-estar, como quando se percorre uma plantação de laranjas ou cafezal em período de floração (ALVES e PAIVA 2010). Os frutos grandes com polpa e mesocarpo comestível podem ser destinados ao consumo local e as folhas, além de exuberantes, apresentam propriedades medicinais.

Finalmente, concordando com ABREU et al. (2009), o uso desta e outras espécies de Passiflora em jardins e quintais é considerada uma forma apropriada para preservar (manter e multiplicar) o germoplasma deste importante gênero neotropical.

\section{CONCLUSÕES}

O uso do maracujá-melão como planta ornamental, conduzida para oferecer sombreamento a outras plantas cultivadas ou áreas externas de lazer em jardins e quintais pode ser indicado como forma do aproveitamento sustentável da biodiversidade neotropical. Pelos resultados obtidos, destacam-se as seguintes vantagens: 1) Plantas grandes e vigorosas de rápido crescimento, folhagem exuberante e desenvolvimento acelerado dos órgãos reprodutivos. 2) Flores em antese simultâneas, abundantes, grandes, fragrantes e coloridas, com um período prolongado de floração no ano. 3) Perfume da flores intenso e agradável, emanado por uma longo período do dia.

\section{AGRADECIMENTOS}

Este trabalho foi desenvolvido como parte da dissertação do autor principal, graças à bolsa de mestrado concedida pelo programa PEC PG, CAPES/CNPq - Brasil. Agradecimento especial a Luis Carlos Bernacci, pela doação de parte das mudas da espécie avaliada.

\section{REFERENCIAS}

ADAMS, R. P. Identification of Essential Oil Components by Gás Cromatography mass spectroscopy. USA: Allured Publishing. Corp, 1995. 469p.

ALVES, S.F.N.S.C.; PAIVA, P.D.O. Os sentidos: jardins e paisagens. Revista Brasileira de Horticultura Ornamental. Campinas, v.16, n.1, p.47-49, 2010.

ABREU, P. P. Passion flower hybrids and their use in the ornamental plant market: perspectives for sustainable development with emphasis on Brazil. Euphytica, Wagenigen, v.166, n.3, p. 307-315, 2009.

AVILÁN, R.L.; LEAL, P.F.; BAUTISTA, D. Manual de Fruticultura. Caracas. Editorial América, 1989. 1475p
BERNACCI, L.C. Passifloraceae. In: WANDERLEY, M.G.L., SHEPHERD, G.J., GIULIETTI, A.M., MELHEM, T.S. (Ed.). Flora fanerogâmica do Estado de São Paulo. São Paulo: RiMa, FAPESP, 2003. v.3, p. 247248 .

FEUILLET, C.; MACDOUGAL, J.M. A new infrageneric classification of Passiflora L. (Passifloraceae). Passiflora, Coconut Creek 13 (2): 34-38, 2003

HADDAD, O.; FIGUEROA, M. Estudio de la floración y fructificación en parcha granadina $P$. quadrangularis L. Agronomía Tropical, Maracay 22(5): 483-496, 1972.

JUNQUEIRA, K. P.; JUNQUEIRA, N.T.V. Espécies nativas do Cerrado com potencial ornamental. In: Simpósio Internacional de Paisagismo, 3, Lavras, MG. Palestras. Lavras: UFLA. 2006 .p.49-54.

JUNQUEIRA, A.H;PEETZ, M.S. Os pólos de produção de flores e plantas ornamentais do Brasil: uma análise do potencial exportador. Revista Brasileira de Horticultura Ornamental, Campinas v.8, n.1-2, p. 25-47, 2002.

KILLIP, E.P. The American species of Passifloraceae. Chicago: Field Museum of Natural History, 1938. 613p. (Botanical Series, 49).

KISHORE, K.K.A.; PATHAK, R.S.; BHARALI, R. Studies on floral biology of passion fruit (Passiflora spp.). Pak. J. Bot. Karachi, v.42, n.1, 21-29p. 2010

MARTIN F.W.; H.Y. NAKASONE. The edible species of Passiflora. Economic Botany. New York v.24, n.3, 333343p. 1970

MELETTI, L.M.M.; OLIVEIRA J.C.; RUGGIERO C. Maracujá. Funep, Jaboticabal. 55 p. 2010. (Série Frutas Nativas, 6).

MELETTI, L.M.M. Caracterização de germoplasma de maracujazeiro (Passiflora spp). Rev. Bras. Fruticultura, Cruz das Almas, v.14, n.2,157-162p, 1992.

OCAMPO, J. Diversity of Colombian Passifloraceae: biogeography and an updated list for conservation. Biota Colombiana, Bogotá v.8, n.1, p.1-45. 2007.

PEIXOTO, M. Problemas e perspectivas do maracujá ornamental. In: FALEIRO, F.G.; JUNQUEIRA, N.T.V.; BRAGA, M.F. Maracujá: Germoplasma e Melhoramento Genético. Planaltina - Distrito Federal: Embrapa Cerrados. 2005. p.457-463.

PIRES, M. V. et al. Germination and seedling growth of ornamental species of Passiflora under artificial shade. Acta Scientiarum Agronomy, Maringá v.34, n.1, 67-75p. 2012 
ROZA, F.A. Estudos reprodutivos e testes de hibridação interespecífica em passifloras silvestres para obtenção de F1. In: Seminário de Iniciação Científica da UESC, 7. 2006 Anais... Ilhéus: UESC. 2006. CD ROM.

SÃO JOSÉ, A.R. Maracujá: produção e mercado. Vitória da Conquista, DFZ, UESB, 1994. 255p.

SCHILLING, B.; KAISER, R.; NATSCH, A. Investiga- tion of odors in the fragrance industry. Chemoecology, Brussels v.20, 135-147p, 2010

ULMER, T.; MACDOUGAL, J.M. 2004. Passiflora: Passionflowers of the world. Portland-Cambridge. Timber press, $430 \mathrm{p}$

VANDERPLANK, J. Passion flowers. $3^{\mathrm{a}}$ ed. Cambridge: The MIT Press, 2000. 224p.
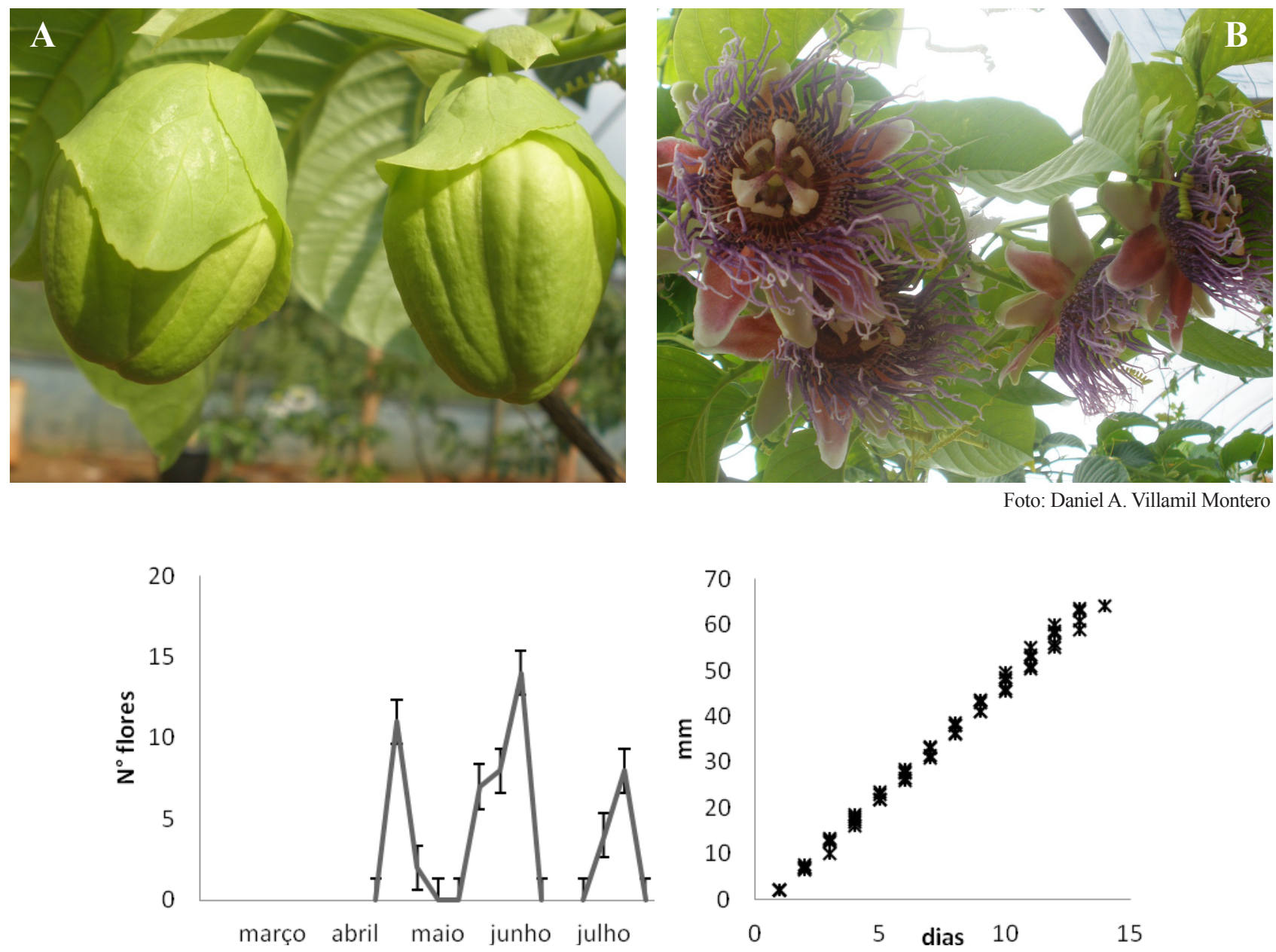

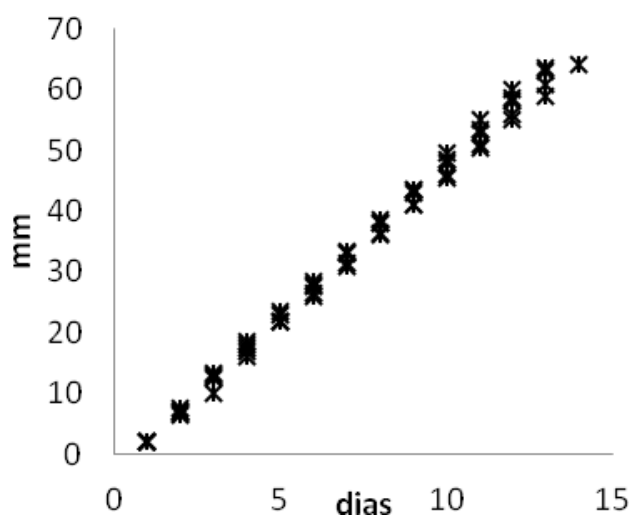

Figura 1. (A) Botão floral em desenvolvimento (B) Flores simultâneas na mesma haste (C) Período e distribuição da floração em cultivo protegido (D) Taxa do crescimento dos botões florais de $P$. quadrangularis em cultivo protegido.

Figure 1. (A) Development of the flower buds. (B) Simultaneous flowers at the same branch. (C) Flowering period and distribution

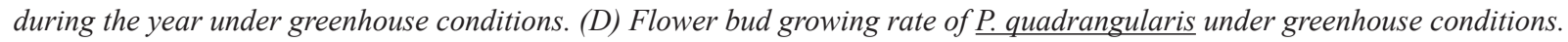




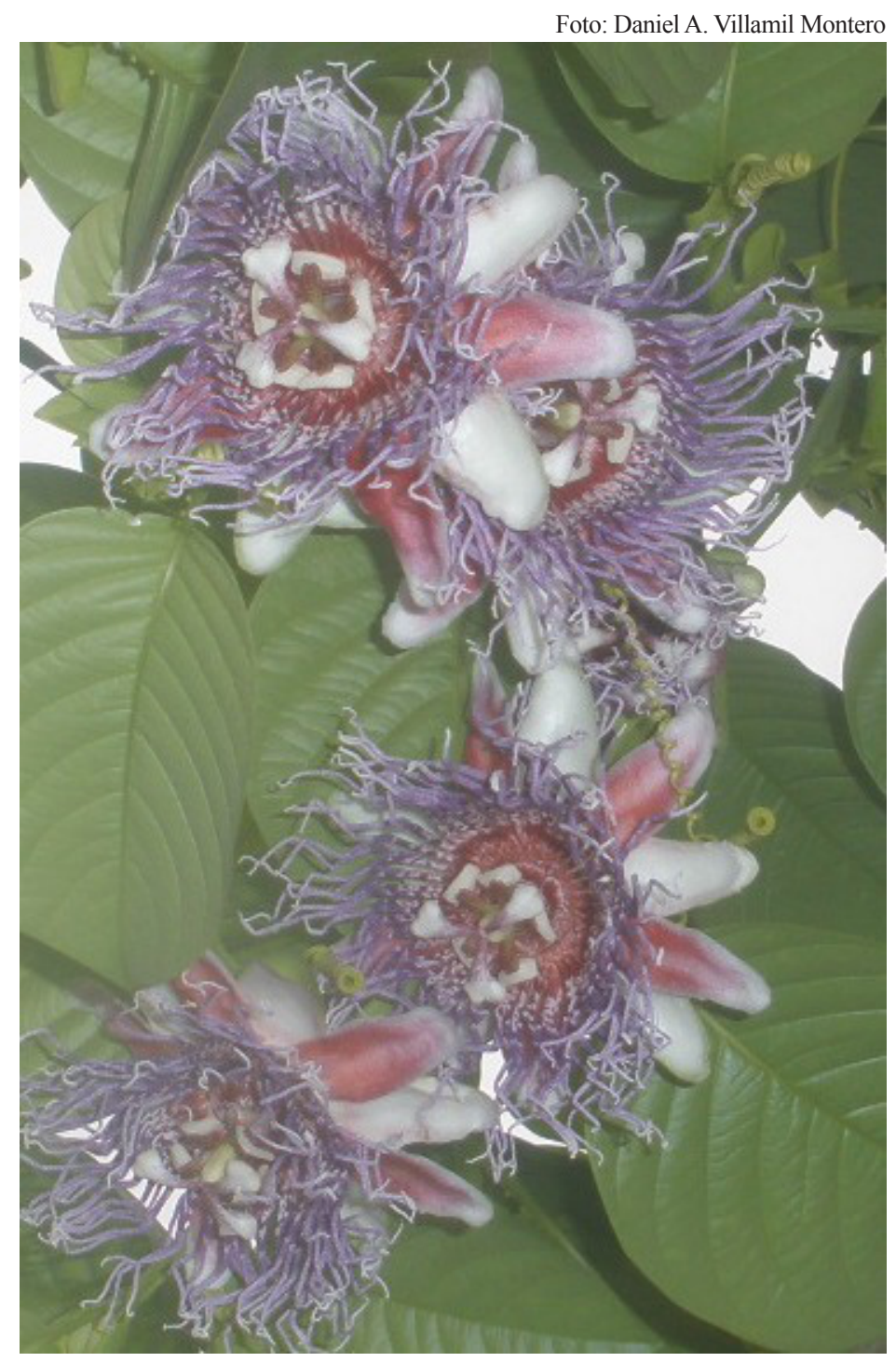

Figura 2. Ramo de P. quadrangularis com várias flores em antese simultânea, pertencente a uma planta cultivada em ambiente protegido.

Figure 2. Bouquet of flowers with simultaneous anthesis in a single branch of a plant of P. quadrangularis cultivated under greenhouse conditions.

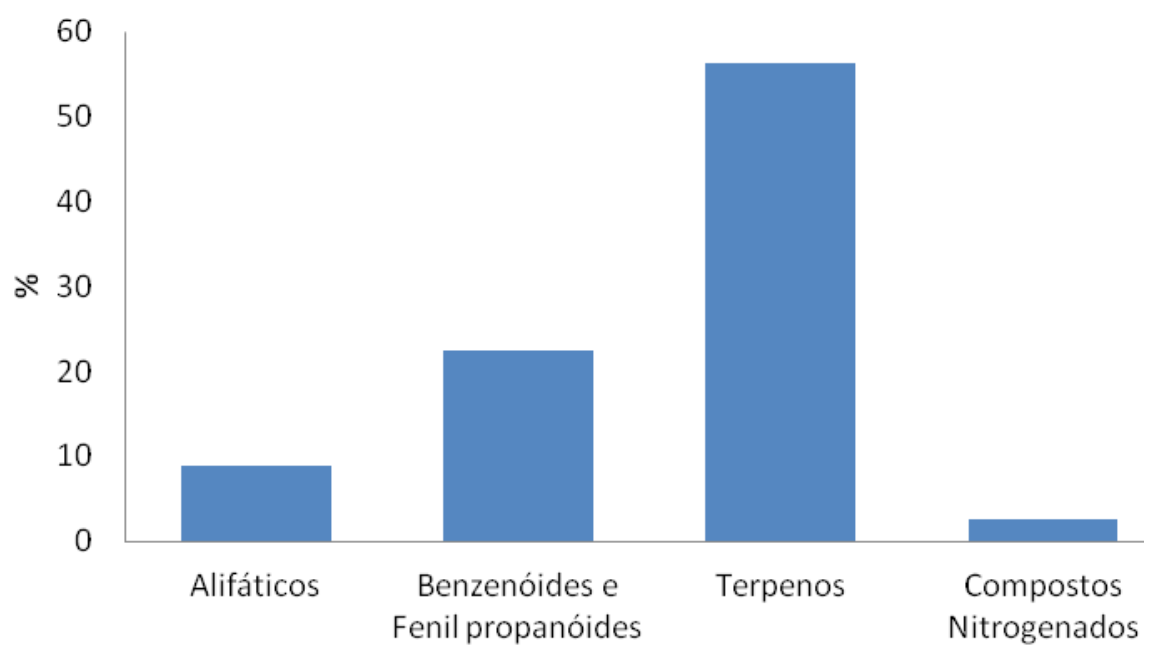

Compostos voláteis

Figura 3. Numero de compostos voláteis capturados no perfume das flores de P. quadrangularis Figure 3. Number of volatile compounds sampled in the floral scent of $\underline{P \text {. quadrangularis. }}$ 